NOTE: The first tuo articles in a 3-part series on the Media-Aided Program in Beginning German at the University of Minnesota follou'. The Ibird article will appear in the Spring issue.

\title{
SMALL-GROUP ACTIVITIES AND THE ROLE OF THE INSTRUCTOR IN MEDIA-AIDED LANGUAGE PROGRAMS
}

by Audrone B. Willeke, Gerhard Clausing, Martha Formanek, and Cecil Wood

Introduction: The Instructional Resources

The concept of Media-Aided Language Programs has been under development at the University of Minnesota since 1962. The program was first applied to the teaching of German, and now is being extended to Swedish and Dutch. Data based on experimentation and testing was used continually to improve the format and sequence. This has led to a program in which a number of learning resources - a programmed textbook, television, computer, audio tapes and small-group meetings with an instructor-are integrated and utilized in several combinations. Table 1 and accompanying diagram present a summary outline of the learning resources and their role in the program. The textbook, television and computer components have been described in other papers'; this report will deal with the role of the instructor and smallgroup activities, presenting our assumptions as well as a description and appraisal of their implementation.

\section{A. Components}

The media aids used in the program function as follows: The students are given a basic presentation of the grammar in the text Programmed German ${ }^{2}$, which introduces the grammatical rules and drills in logical increments. Bi-weekly television grammar sessions,

\footnotetext{
'Martin Kuelbs, "The Genesis and Development of Programmed German," Research Report of the Consulting Group on Instructional Design, University of Minnesota, forthcoming (1973). Martha Formanek, Gerhard Clausing, and Cecil Wood, "The Contribution of Television in Media-Aided Language Programs," forthcoming, Gerhard Clausing and Cecil Wood, "The Computer-Tutor in Media-Aided Language Programs," forthcoming.

${ }^{2}$ Cecil Wood, Charlotte von Wymetal, and Wolfgang Taraba, Structural German (Minneapolis: Gilbert Publishing Co., 1965). Revised edition by same authors entitled Programmed German (Minneapolis: University of Minnesota, 1971). A totally revised and expanded program, Deutsch. A Media-Aided Language Program is planned.
} 


\section{Small Group Activities}

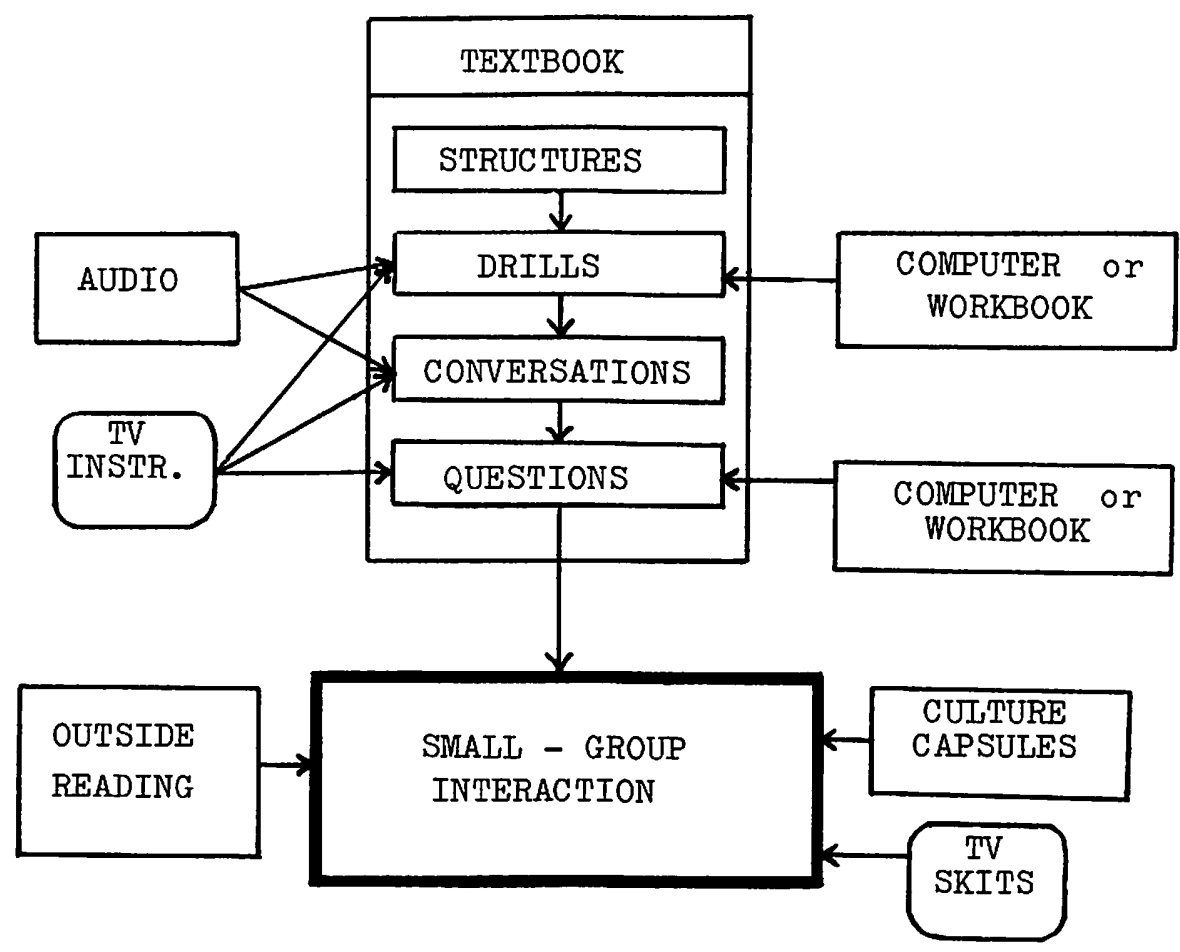

Diagram 1. INTERACTION OF INSTRUCTIONAL CONPONENTS IN MEDIA - AIDED LANGUAGE PROGRAMS 


\begin{tabular}{|c|c|c|}
\hline $\begin{array}{l}\text { Learning } \\
\text { Resourcos }\end{array}$ & Functions & Schedulling \\
\hline $\begin{array}{l}\text { Small } \\
\text { Groups } \\
\text { w1th } \\
\text { Instructor }\end{array}$ & $\begin{array}{l}\text { 1. Active use of the target language } \\
\text { a) Pronunclation } \\
\text { b) Guided conversations on readings, IV materials, } \\
\text { c) Origning tapes, cultural topics } \\
\text { c) } \\
\text { 2. Motivation and attention to individual problems } \\
\text { a) Variety in topics and activities } \\
\text { b) Creativity-time and freedom to experiment } \\
\text { c) Interpersonal communication } \\
\text { 3. Coordination of all components } \\
\text { a) Reworking of topics and vocabulary from } \mathrm{TV} \\
\text { and audio tapes } \\
\text { b) Reinforcement of learned structures in con- } \\
\text { versational context } \\
\text { 4. Evaluation of performance } \\
\text { a) Oral testing } \\
\text { b) Written quizzes and final exam }\end{array}$ & $\begin{array}{l}3 \text { times } \\
\text { per week }\end{array}$ \\
\hline \multirow[b]{2}{*}{$\begin{array}{l}\text { Media } \\
\text { Alda }\end{array}$} & $\begin{array}{l}\text { 1. Television (grammar explanations, drills, quizzes, } \\
\text { skits) }\end{array}$ & $\begin{array}{l}2 \text { times } \\
\text { per weok }\end{array}$ \\
\hline & $\begin{array}{l}\text { 2. Computer (algorithms, drills, questions, spelling) } \\
\text { 3. Audio Tapes (pronunciation, drills, dialogues, } \\
\text { listenlng tapes on cultural topics) } \\
\text { 4. Programmed Text (Structures, drills, conversations, } \\
\text { questions) }\end{array}$ & $\begin{array}{l}\text { flexible } \\
\text { pacing }\end{array}$ \\
\hline
\end{tabular}

Table 1. Small Group Activities and the Role of the Instructor in 


\section{Small Group Activities}

which also include drill practice, augment and reinforce the text explanations. Furthermore, dramatized skits shown on television not only help to develop aural comprehension, but also expose the student to the culture of the new language and to a broad range of colloquial expressions, idioms and vocabulary. The computer component, currently used by about 20 per cent of the students, serves as a grammar "tutor" for doing homework. In addition to step-by-step mastery of the grammar, the computer also provides efficient review for students with specific grammatical problems. Furthermore, performance data stored in the computer make it possible to examine each student's progress, help determine the cause of grammatical difficulties and improve the instructional program itself; it is not utilized for evaluation of the student's performance. Audio tapes supplement the textbook and aid the students in pronunciation. In the latter part of the first year a few audio tapes on cultural topics, such as the German school system, or German family life, are used to give students added practice in aural comprehension.

\section{B. Implications}

Student mastery of the grammatical structures is thus achieved by drills on television and with the audio tapes, as well as on the optional computer. As a result, the assumption is made that no grammar explanations or repetitive drilling is needed in the classroom. The problem of how to structure the three weekly group meetings becomes a crucial one. Since the instructor is relieved of teaching and drilling grammar, there is more time and more freedom to include interesting and creative activities than in a conventional course. From the very beginning of instruction, classroom sessions are designed for active practice of the language elements, which the students are learning with the aid of media. As their knowledge of grammatical structures and vocabulary expands, the types of conversational activities which can take place in the group sessions increase as well. The general assignment schedule allows each instructor some variation in structuring the group meetings as desired.

The experience of instructors teaching in this program indicates that the students feel more free to speak the new language without irhibitions in an informal atmosphere. The atmosphere desired in the classroom can be described as "structured informality", i.e. seemingly $a^{\text {r-h }}$-hc discussions, carried out in an informal atmosphere, are structured by the instructor, linking the discussion to the language goals to be mastered, in particular to specific increments of grammar and to pre-selected vocabulary. 


\section{A. Importance of group interaction}

The media components (textbook, television, computer and audio tapes) have a subordinate, preparatory role, and are used merely as tools by the instructor, whereas the activities which take place in the classroom are central to the program. Since the instructor ties together and utilizes all of the above resources in the classroom, the use of media in no way diminishes the importance of group interaction or of the classroom instructor.

The significance, according to student perception, of group interaction with the instructors was clearly indicated by the results of a survey distributed to all first year German students (a total of 593) in the fall of 1972. Among other items the students were asked for an evaluation of the various elements of their language program. We asked for responses to the following question:

"Please rank (as applicable) the learning resources in beginning German in order of their usefulness and helpful. ness to you in learning German."

Text
Instructor
Language tapes
CCTV
Computer

The students were asked to rank these items on a five point scale, where " 1 " was the most favorable and " 5 " the least favorable evaluation. Table 2 presents the compiled results expressed in terms of the mean for each group. The results indicate that in all the courses, in the traditional and even more so in the media-aided, the students considered the instructors to be the most important factor in the program.

The importance of group interaction with the instructor in beginning language was underscored further in an experimental approach which was instituted in Fall Quarter 1972. On the assumption that the beginning German students needed considerable input-mastery of some grammar structures and a minimum vocabulary-before they could participate in oral work, the class sessions for the computer sections were reduced from three meetings a week to one during the first quarter. Instead, the students were expected to devote more time to practice on the computer. The one class session was used to practice pronunciation and to give individual help. Although the basic assump- 


\section{Small Group Activities}

tion underlying this experimental approach may be correct, i.e., that students cannot be taught the basic grammar and vocabulary, but that they must learn it themselves, the experiment was nevertheless not a success in the estimation of most instructors and students.

Student survey results suggest that motivation suffered; students seemed to feel abandoned and some became too isolated. Although instructors were available at all times for consultation, students rarely availed themselves of them. The single class meeting a week seemed insufficient to establish a good personal relationship between instructors and students. For such an approach to succeed, provisions have to be made for frequent informal contact between instructors and students. These contacts could be either on a one-to-one basis, or in small groups. The Germanic Languages Instruction Center, functional at the University of Minnesota beginning Fall 1973, offers improved conditions for such informal contacts on the basis of need, by providing in a congenial atmosphere areas for group work and individual student-instructor contacts. In this Center, all media resources are available in special, easily accessible areas.

\begin{tabular}{|c|c|c|c|}
\hline \multicolumn{4}{|c|}{$\begin{array}{l}\text { STUDENT EVALUATION: MEAN VALUES } \\
\begin{array}{ll}\text { 1=very helpful and useful } & \text { 3=neutral } \quad \text { 5=least helpful and useful } \\
\text { 2=helpful and useful } & \text { 4=not helpful or useful }\end{array}\end{array}$} \\
\hline $\begin{array}{l}\text { Learning } \\
\text { Resources }\end{array}$ & $\underset{\substack{I \\
\text { Toleviaion-aided } \\
(N=104)}}{ }$ & $\begin{array}{c}\text { II } \\
\text { Computer and } \\
\text { Tolovision-aided } \\
(\mathrm{N}=21)\end{array}$ & $\begin{array}{c}\text { III } \\
\text { Traditional } \\
(\mathbb{N}=195)\end{array}$ \\
\hline Instructor & $\stackrel{1.25}{\sim}$ & $\overbrace{}^{1.48}$ & $\overbrace{}^{1.96}$ \\
\hline Text & 1.72 & 1.62 & 2.68 \\
\hline Computer & - & 1.62 & - \\
\hline Tapes & 2.77 & 2.28 & 2.82 \\
\hline CCTV & 2.68 & 2.48 & - \\
\hline
\end{tabular}

Table 2. Student evaluation of learning resources in first quarter of Beginning German. 


\section{Diagram 2}

GERMANIC LANGUAGES INSTRUCTION CENTER:

The instructional setting as part of the

Learning Resources Center at the University of Minnesota

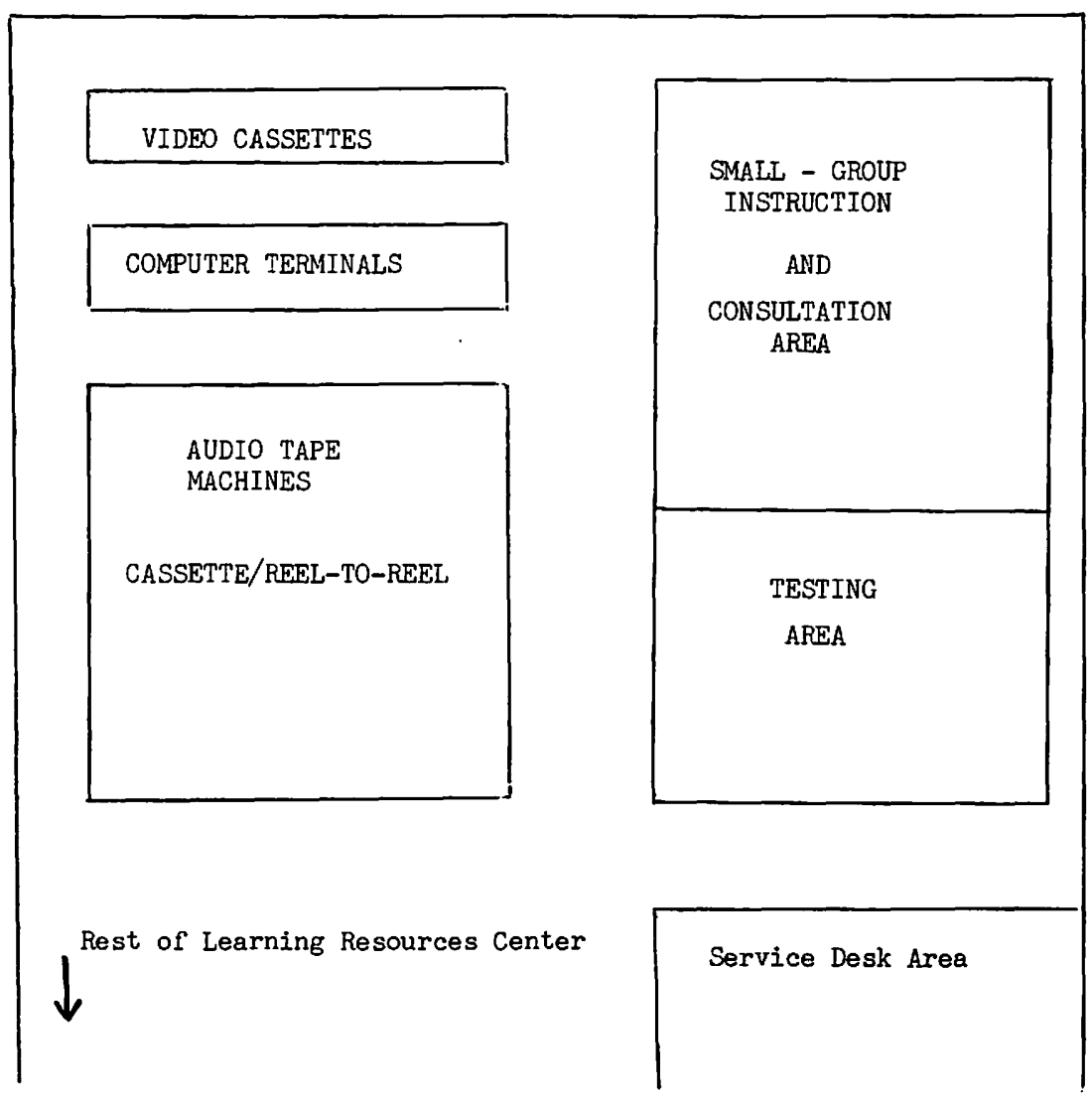




\section{Small Group Activities}

B. The functions of group interaction

In order to ascertain the instructors' perception of the functions of the classroom, those who recently taught in the program were asked to respond to the following two questions in personal and confidential interviews conducted during Spring Quarter 1973:

"What do students get in class which they cannot get any other way?"

"Ideally, what function should the classroom perform in mediaaided language teaching?"

Almost all of the answers fell into two catagories:

The classroom should:

1) stimulate active use of the language in semi-realistic conversational situations

2) provide individual attention to problems and increase learning motivation

Other data gathered through the personal interviews and class visits bring out two further tasks which must be assumed by the classroom in a media-aided language program:

3 ) integration of the various program components into a meaningful whole

4) evaluation of student performance

We will now look in detail at the task of the classroom within each of these four areas, and describe how these objectives are presently being at least partially achieved in the media-aided Beginning German instruction at the University of Minnesota.

\section{Active Use of the Language}

Active use of language requires relevant conversational situations in which the student must pull together all that he has learned in order to comprehend and respond to a linguistic or non-linguistic stimulus. Straight recitation of memorized dialogues or manipulation of grammatical forms in oral drills has been found too limiting as well as boring and are avoided in the classroom.

Instructors are given the following general outline for the course: FIRST QUARTER: As is customary in many other programs in the first few weeks acceptable pronunciation ard intonation habits are established in a "prereading stage", through practice of words in context and useful phrases. The dramatization of dialogues, whereby students speak the various roles, is a frequently used technique, as written texts are gradually introduced. Questions and answers based on structures and vocabulary learned in Programmed German are included beginning with the third week. In the second half of the 
first quarter, the interchange of questions and answers deals with short reading assignments and six skits which the students have seen on television.

SECOND QUARTER: The students progress to less structured conversations. They are asked to summarize or to retell in their own words the assigned stories and television skits. In the first two quarters the students are expected to give quick responses to the questions-to "react" in German in order to avoid habitual translation from the student's native tongue into the new language.

THIRD QUARTER: By this time, guided discussions in German occupy an average of about 70 percent of class time. The topic of these discussions is most frequently related to the readings; ${ }^{3}$ however, television skits, cultural materials heard on audio tapes, and topics of cur. rent interest to students are also incorporated, depending on the personal choice of the instructor. The discussions are organized and initiated in a variety of ways. Among the more frequent techniques used by the instructors are: question and answer interchanges between instructor and students or among the students; student summaries of material read or of skits seen on television; reenactment of skits viewed; reactions to pictures used as conversational stimuli. Some student-initiated activities, such as presentations of original skits, or discussions of outside readings chosen according to individual interest, are conducted by dividing the class into smaller groups to insure maximum participation.

Although variations among instructors have been noted, on the average approximately 20 percent of class time is spent in answering questions, administering quizzes, quick reviewing of learning material and homework. However, it is felt that reviewing written assignments during group meetings does not constitute the most profitable use of class time and instructors are generally advised against it. Another average 10 percent of class time is devoted to periodic motivational

'During 1972-74 academic years, the following reading materials were used, in addition to reading passages in Programmed German:

First Quarter, F. G. Ryder and E. A. McCormick, Lebendige Literatur, (Boston: Houton Mifflin Co., 1960).

Second Quarter, K. Sparks and E. Reichmann. So ist es! (New York: Harcourt Brace Jovanovich, 1972). Van Horn Vail and Kimberly Sparks. Der Weg zum Lesen. (New York: Harcourt, Brace and World, 1972).

Third Quarter, Der Weg zum Lesen, continued. Goscinny and Uderzo, Asterix und die Goten (Stuttgart: Ehapa-Verlag, 1971). Peter Bichsel, Kindergeschichten. (Koln: Luchterhand, 1972). 
activities, such as word games, crossword puzzles in German, humorous sight passages. Students also take turns playing "tourist guide" and leading the class through some area of Germany, accompanying the presentation with slides and pictures. According to instructor estimates, the use of German in classroom interaction increases from about 40 to 50 percent in the first quarter to between 70 and 90 percent in the third quarter. The goal toward which the instructors always strive is 100 percent, though this is seldom achieved.

Although oral work is stressed in the group meetings, the other skills are not neglected in the total program. Fairly extensive reading materials are assigned in the second and third quarter. Writing skill is developed through composition tasks and additional work sheets, which stress particular grammatical structures and provide review. Students in the computer sections receive extensive spelling practice by typing drill sentences at the terminals, which are immediately corrected by the computer.

\section{Motivation and Attention to Individual Problems}

Within the total program the classroom retains the primary responsibility for fostering motivation. Evidence to support this has been cited above, in the section "The Role of the Classroom." The primary function of language-communication-presupposes interpersonal relationships. Language learning is essentially a social act, an interpersonal or group effort. The students need reassurance by the teacher and the mutual support of the group. The urge to communicate within a groun is a force that must be utilized to increase motivation for language learning.

The instructor, freed from the need to explain and drill grammar, can motivate students through variety, spontaneity and creativity of activities in the classroom. He can also "exploit" the media aids in several ways in order to have a positive effect on the motivation and interest of the students in the group meetings. As has been mentioned above, television introduces a great variety of topics and situations that can be incorporated into class work. The visual impact and sophistication of the television skits, with their frequent humor and recreation of real-life situations, could never be reproduced by a single teacher in the classroom. The visual appeal of the skits can be utilized as a motivating factor in class work.

The group meetings can also do much to humanize the machines, the technical media used as aids in the learning process. In previous years, some students enrolled in computer instruction only, as independent study, and did not attend classroom meetings or have other regular contacts with human instructors. Many of them did not finish 
the entire program. It was repeatedly stated by these students that they felt frustrated by the lack of human contact. In some cases, it has caused them to attribute human characteristics to the machine. For example, a "human identity" was created for the computer and its minor malfunctions, which would otherwise have caused frustration, but could be smoothed over by attributing them to "Oskar's" ornery personality or his simplemindedness or poor health. This studentgenerated phenomenon was exploited successfully in the same program used at the University of Minnesota, Duluth. For those students the computer, "Oskar" became a group mascot.

\section{Integration of components}

Group activities, guided by the classroom instructor, must bring together and reinforce for the student the input which he has received from the media components and must help to transform this knowledge into an active skill. The task of integration is attempted in the classroom in the following ways:

1) The grammar explanations and drills presented in the textbook, in the television sessions and individually practiced at the computer terminal are reinforced in class by using the same structures in a different context. In addition, worksheets, which are study guides for the essential parts of each chapter, are distributed regularly and also help the students review the material recently presented on television.

2) Aural comprehension and the student's ability to speak the language increase through rephrasing, retelling and discussing television skits and listening tapes in the classroom. Since the students are not given any written material on the topics presented in the skits and on the audio tapes, except for the essential vocabulary, the students have to concentrate and can rely only on their aural comprehension. Furthermore, vocabulary and idiomatic expressions presented orally through the media are reinforced in classroom conversations. Students are given written assignments and quizzes on the skits and on the audio tapes which encourage them to transform the spoken word into written form.

3) The television teacher periodically gives the students questions or other tasks which are to be solved in the class meetings with the help of their own instructors.

Thus it is evident that textbook, television, computer and audio tape components are integrated into a total and comprehensive learning program through the active use of the same materials in varied form in the classroom. In order to do this successfully, the instructor must be well acquainted with the entire program and must plan the 


\section{Small Group Activities}

group sessions carefully. Some of the problems encountered in coordinating the program components are discussed in the concluding remarks.

\section{Evaluation of Performance}

The student's progress in learning the new language is evaluated mainly on his performance in that language within the group. Comprehension and oral expression throughout the quarter constitute about 50 percent of the grade. Writing skill, tested through written assignments and quizzes, constitutes another 25 percent and the final exam, which has both written and oral sections, the remaining 25 per cent.

It was found that traditional tests for the most part have consisted of nothing more than a reiteration and confirmation of items to which the student was exposed in the course. Thus such tests were as much a check on memory ability as an attempt to verify in a very limited way the ability to apply grammatical structures. Consonant with our goals for the language student-the attaining of the skills needed to communicate-we are interested in testing the students' ability to integrate what has been transmitted by the various media components toward the generating of correct spoken or written strings for meaningful communication. Two of the main considerations exemplified by the techniques outlined below have been: to isolate each particular skill as it is being tested, and to present all language tasks within textual contexts.

The first part of the examination tests comprehension of written texts. Students read sight passages in German and are asked questions, which are to be answered in English. The second part of the examination tests the student's ability to generate original German texts, by asking them to describe a series of pictures in brief essays. Aural comprehension is checked by playing an audio tape of short conversations in German. Students answer the dictated questions on the conversation in English. It is too early to reach definite conclusions on the basis of these experiments. However, it was noted that the computer-aided groups performed better in all the skits tested. Refinement of testing techniques continues and results will be reported at a later date.

\section{Problem Areas and Outlook}

In evaluating our Media-Aided Program, the instructors saw several major advantages in the present organization. Almost all (11 out of 14) mentioned that programmed learning and the technical media provided the optimal conditions for the active use of language and for giving the student individual attention to problems. Most instructors (10 out of 14) also welcome the variety which the tele- 
vision programs provide. Two-thirds of the instructors presently engaged in the program prefer to teach in this program rather than in a more traditional method, if given an option. This is the case even though class preparation, especially in the first quarter, is more demanding than in other beginning language courses. However, several problem areas have been recognized in the present program: (1) choice and preparation of instructors and (2) coordination.

(1) Preparation of instructors. In spite of the relatively great amount of freedom to structure classroom activities within the provided framework of the system, basic agreement on method and objectives is needed. Although the instructors generally accept the design and the goals of the course, many of them are used to including grammatical explanations in class work and find it difficult to abandon this habit.

The program also requires a willingness to work as part of a team; that is with the television teacher and the other media. In this partnership, a sharing of tasks is necessary if classroom interaction is to accomplish the envisioned goals. The instructor's attitudes are most important for the success of the program. Most language teachers do not possess team experience as part of their background. They learned the foreign language from a succession of single teachers, who represented the sole authority in the classroom. These models and subsequent teaching experience do not prepare the instructor for the sharing of tasks which the program demands. Thus a more through training and immersion program is now used for instructors just beginning the program. In this program they learn about the role and potential of technical media and examine language teaching methods and objectives with emphasis on team work. A continuing workshop throughout the year, in which the program is constantly subjected to critical review and instructors share common problems and practical techniques, helps to implement team work. Since the success of the classroom in Media-Aided Language Programs depends largely on the introduction of stimulating activities by the instructors, more help can be provided here, especially for those pressed for time. A suggestion file that pools the ideas of all instructors on group activities, discussion topics, vocabulary displays (lexical subsystems) and varied approaches to reading material is now being prepared together with visual aids and realia. This will be both a time-saving device and a means of structuring class activities more carefully.

(2) Coordination. Greater coordination of components, especially of audio tapes and television, with the classroom activities is needed. The student survey indicates that the audio tapes and television are 


\section{Small Group Activities}

perceived as being somewhat less integrated into the total program.4 Presently, instructors are not always fully aware of what is being done in each television session.

Coordination between television and class work is at times haphazard, depending on the cooperation of the individual instructor, and moves presently in a one-way direction. The classroom teacher could also make supplementary television tapes as well as computer drills when desired. For example, television will also be utilized to reinforce the reading material and to support the cultural materials of the listening tapes. Such "culture capsules" on video cassettes will help to satisfy a variety of student objectives for beginning German.

The design of the Media-Aided Language Program is readily adaptable for Individualized Instruction. The programmed textbook and accompanying audio tapes, the computer and video tapes make it possible for students to progress through the grammar at their own pace, to review and repeat as needed. With the introduction of the Individualized Instruction sequence for German at the University of Minnesota in the Fall of 1973, flexibility in group sessions, reading selections, testing schedule and credit allotment will also be applied to this Program.

The first and only fully functioning television and computerassisted program for the teaching of German, through the experimental approach with which it was initiated and conducted, has generated much data ${ }^{5}$ on the process of learning a new language, has led to new approaches in testing and to a development of team work between group instructors and the television teacher, and between the instructors and the media aids.

Although improvements are constantly being implemented and a revised edition of the programmed textbook is underway, the basic design of the program can be expanded to other institutions, as well as to the teaching of other languages. The program as a whole, or some of its components, have already been adopted by other colleges and high schools. The television skits series, in particular, can be an enriching addition in any Beginning German course.

4The students were asked to rank on a scale from 1-5, where 1 was the most positive and 5 the most negative response, the various combinations of resources, indicating to what extent these elements are brought together effectively and efficiently. The mean for "instructor and tapes" was 2.31 and for "instructor and CCTV" 2.05, whereas "instructor and text" was ranked highest, 1.61 .

sForthcoming as research reports from the Consulting Group on Instructional Design, University of Minnesota. 